\title{
Inter-influence of Temperature-time-reflectivity in the Coal Metamorphism Thermodynamics Equation (CMTE)
}

\author{
Zhang Xuemei ${ }^{1, ~ *, ~ M a ~ Q i n g h u a ~}{ }^{1}$, Li Dong ${ }^{1}$, Hao Jingyuan ${ }^{1,2}$ \\ ${ }^{1}$ Energy \& Chemical Engineering Research Center, Xi'an Siyuan University, Xi'an, China \\ ${ }^{2}$ College of Chemical Engineering, Xi'an Jiaotong University, Xi'an, China \\ Email address: \\ 476333285@qq.com (Zhang Xuemei),854042134@qq.com (Ma Qinghua), zuizuixuan123@163.com (Li Dong), \\ 923716217@qq.com (Hao Jingyuan) \\ ${ }^{*}$ Corresponding author

\section{To cite this article:} \\ Zhang Xuemei, Ma Qinghua, Li Dong, Hao Jingyuan. Inter-influence of Temperature-time-reflectivity in the Coal Metamorphism \\ Thermodynamics Equation (CMTE). International Journal of Economy, Energy and Environment. Vol. 6, No. 5, 2021, pp. 114-117. \\ doi: $10.11648 /$ j.ijeee.20210605.16
}

Received: September 3, 2021; Accepted: October 15, 2021; Published: October 19, 2021

\begin{abstract}
The influence and control of time and temperature on coalification are comprehensive. In order to quantitatively analyze the thermal kinetics of coal metamorphosis process by temperature and time, the qualitative analysis of coal metamorphosis thermodynamic equation (CMTE) based on Wu Chonglong was further verified from the mathematical point of view. Wu Chong Long's Coal Metamorphism Thermodynamics Equation (CMTE) is a ternary equation containing coal forming period or metamorphic age (time), metamorphic temperature (temperature) and metamorphic degree (reflectivity). The temperature calculated by fixing time and reflectivity is the lowest theoretical metamorphic temperature. The reflectivity calculated by fixing time and temperature is the maximum theoretical metamorphic degree. The "time-temperature ratio" is defined as the equivalent of extending million years to increasing $1^{\circ} \mathrm{C}$ temperature regarding coal metamorphism. This ratio is used to compare the impact of extending time or increasing temperature on improving the metamorphic degree and its significance. The results showed that in the same coal forming period, the ratio is decreased with the reflectivity increasing; at the same reflectivity, the ratio decreased with younger coal forming period. At $R_{0}=6.1 \%$, the calculated ratio is 3.67 , which means, at $\mathrm{R}_{\mathrm{o}}=6.1 \%$, increasing $1^{\circ} \mathrm{C}$ is equaled extending 3.67 million.
\end{abstract}

Keywords: Coal Metamorphism Thermodynamics Equation, Minimum Metamorphic Temperature, Maximum Metamorphic Degree, Time-temperature Ratio

\section{Introduction}

The developmental process from peat to lignite, to subbituminous coal, bituminous coal, until to anthracite, is called "Coalification" or "metamorphism". Because coal chemistry is the physical and chemical structure changed under the temperature, pressure and time and other factors. In general, even if the influence and control of metamorphism are comprehensive, but the degree is mainly controlled by two external influence factors (temperature and time), and the metamorphism degree is indicated by the reflectivity [1, 2]. It is well known that there is a difference between qualitative and quantitative, qualitative is described in literal language, while quantification is described in mathematical language. For example, Wu Chong Long and Yang Qi, according to the general principle of thermal and chemical dynamics, referring to the Bostick curve and the measured data in China, use the dual regression method have established a three-variable empirical formula of temperature -time -reflectivity [3-6] Coal Metamorphic Thermodynamics Equation (CMTE). So far, the CMTE is rarely used to verify the qualitative analysis of coal metamorphic thermal dynamics. To this end, this article tries to solve the following three problems: calculating the minimum metamorphic temperature for coal with known absolute age and reflectance; calculating the maximum reflectance for coal with known absolute age and reflectance; and quantitatively explaining which of the two factors, temperature rise and time extension, has a greater influence on improving coal metamorphism. 


\section{Data and Equation}

\subsection{Coal Metamorphism Thermodynamics Equation}

HOOD proposed ternary plot [7] representing temperature - time - reflectivity in 1975. BOSTICK in 1979 [8] indicates temperature-time- reflectivity, according to the exploration data of the Los Angeles Basin and Ventura Basin. With temperature as the dependent variable and time and reflectivity as the independent variables, Wu Chong Long proposed the formula [3] for temperature-time- reflectivity in 1997 as following:

$$
\ln (T-273)=\frac{646.32}{\ln t+111.85}-\frac{0.492 t^{0.093}}{R_{o}}
$$

Where

t: "absolute age" or "effective heat time", million years;

$\mathrm{R}_{\mathrm{o}}$ : reflectivity, \%;

$\mathrm{T}$ : temperature, $\mathrm{K}$.

When the formula with reflectivity as the dependent variable and time and temperature as the independent variables transform as:

$$
\mathrm{R}_{\mathrm{o}}=\frac{0.492 \mathrm{t}^{0.093}}{\frac{64632}{\ln \mathrm{t}+111.85}-\ln (\mathrm{T}-273)}
$$

Different paleogeothermal measurement methods have their own preconditions, accuracy and results. Because the evolution degree of deep forming metamorphic coal always corresponds to a certain configuration of structural settlement, geothermal action and effective heating time, the effective heating (metamorphic) time is also determined according to the coal seam reflectivity contour and the existing fold form of tectonic settlement. However, in any case, the effective heating (metamorphic) time is less than or equal to the absolute age of the rock formation. Effective heat response (metamorphic) time and paleoground temperature are two controversial data.

\subsection{Coal Forming Period}

Even if there are several coal forming periods in China, but three periods which generated wide rank coals from low order coal (long flame coal) to high order coal (anthracite) are:

Carboniferous to Permian: about 320 million-278 million years ago. The time span is 42 million years, or the Carboniferous period. Carboniferous was the earliest coal resource formation period. Carboniferous coal in China was basically distributed in the Yellow River basin, and coal ranging from long flame coal to anthracite.

Early and middle Mesozoic Jurassic: about 205 million to 159 million years ago. The time span is 46 million years, simply for the Jurassic. Jurassic coal was mainly concentrated in the border between Inner Mongolia, Shaanxi, Gansu, four provinces of Ningxia and northern Xinjiang, coal ranging from lignite, flame coal to anthracite.
Early Mesozoic Cretaceous: about 142 million-99 million years ago. The time span is 43 million years, simply the Cretaceous. Cretaceous coal was distributed in eastern Inner Mongolia and the three northeastern provinces of Inner Mongolia. Cretaceous coal species in the three northeastern provinces range from long flame coal to anthracite.

Although the absolute age difference of the three coal forming period is 220 million years, there are two particularly significant points in common. First, all three coal forming periods are able to generate a coal range from long flame to anthracite, that is, the same metamorphic span. Second, the time span of the three coal forming periods is also basically equal, namely, from 42 million to 46 million years.

\subsection{Reflectivity}

The reflectivity of the long flame coal is $R_{0} \geq 0.50 \%$. The reflectivity of other bituminous coal species (gas coal, fat coal, coking coal, lean coal, weak sticky coal, and non-adhesive coal) can refer to reference [9]. The 11 coal classification according to the vitrinite reflectance can refer to the Chinese coal industry standard [10]. The reflectivity of long flame coal to the last bituminous before reaching anthracite was set at between $0.52 \%$ and $2.83 \%$ [11].

\section{Results and Discussions}

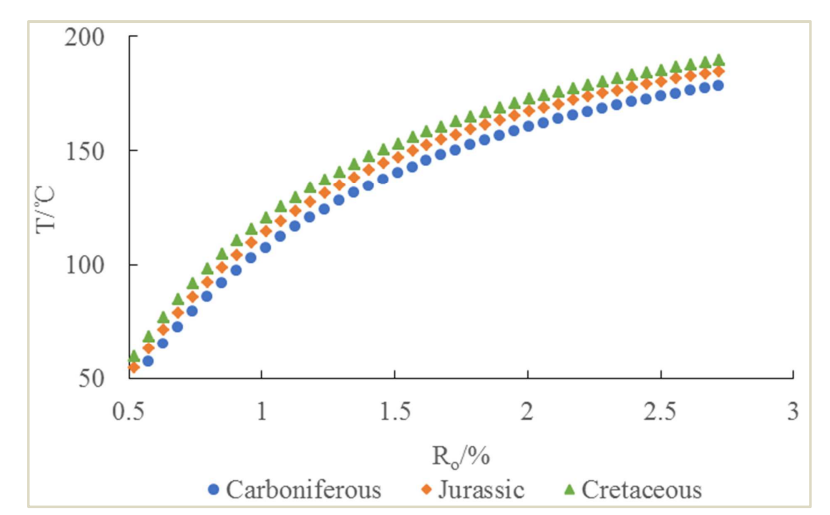

Figure 1. Three coal forming periods form three temperature-reflectivity (time) curves.

Based on the same metamorphic span and time span characteristics, a two-dimensional diagram showing the temperature-reflectivity (or time) is now designed. The reflectivity of the selected long flame coal to anthracite was divided into 42 same increment $(2.83 \%-0.52 \%) / 42=0.055 \%$. The increment of reflectivity is $0.055 \%$, but the increment of time is one million years. For example, the starting reflectivity of the Carboniferous was $\mathrm{R}_{\mathrm{o}}=0.52 \%$, and the Carboniferous start time was 278 million years, $t=278$. The starting temperature of the Carboniferous was $49.4^{\circ} \mathrm{Cby}$ equation (1). The second point condition of the Carboniferous was $\mathrm{R}_{\mathrm{o}}=0.52+0.055=0.575 \%, \mathrm{t}=278+1=279$, and the second point temperature of the Carboniferous was calculated by equation (1) as $57.6^{\circ} \mathrm{C}$, and so on. Three coal forming periods form three temperature-reflectivity (time) 
curves, as shown in Figure 1. The Carboniferous is the lowest line. The Jurassic is the intermediate line. The Cretaceous is the top line. The longitudinal axis of Figure 1 indicates the temperature. The horizontal axis is the reflectivity, and also the time.

\subsection{Minimum Temperature}

At the beginning, it is emphasized that the actual metamorphic time is less than the coal forming period. At the longest metamorphic time is equal to the coal forming period. If the coal forming period and the reflectivity are two available data, which can be input into equation 1 , it should be recognized that the calculated temperature is the minimum metamorphic temperature.

Table 1. The minimum temperature $\left(T_{m}\right)$ required to reach different reflectivity $\left(R_{o}\right)$ at different rock absolute ages $(R A A)$.

\begin{tabular}{lllllll}
\hline \multirow{2}{*}{$\mathbf{R}_{\mathbf{0}} / \%$} & \multicolumn{2}{l}{ Carboniferous } & \multicolumn{2}{l}{ Jurassic } & \multicolumn{3}{l}{ Cretaceous } \\
\cline { 2 - 7 } & RAA/m.a. & $\mathbf{T}_{\mathbf{m}} /{ }^{\circ} \mathbf{C}$ & RAA $/ \mathbf{m} . \mathbf{a}$. & $\mathbf{T}_{\mathbf{m}} /{ }^{\circ} \mathbf{C}$ & $\mathbf{R A A} / \mathbf{m} . \mathbf{a}$. & $\mathbf{T}_{\mathbf{m}} /{ }^{\circ} \mathbf{C}$ \\
\hline 0.52 & 280 & 49.4 & 161 & 54.9 & 101 & 60 \\
0.96 & 288 & 102.6 & 169 & 109.7 & 109 & 115.8 \\
1.4 & 296 & 134.4 & 177 & 141.6 & 117 & 147.6 \\
1.84 & 304 & 154.7 & 185 & 161.6 & 125 & 167.2 \\
2.28 & 312 & 168.6 & 193 & 175.2 & 133 & 180.5 \\
2.72 & 320 & 178.6 & 201 & 184.9 & 141 & 189.8 \\
\hline
\end{tabular}

\subsection{Maximum Vitrinite Reflectance}

If the coal forming period and the metamorphic temperature are two available data, which can be input into equation (2), it should be recognized that the calculated reflectivity is the maximum reflectivity.

Table 2. Maximum reflectivity (Rom) of coal at different absolute ages (AA) and temperatures of strata (Ts).

\begin{tabular}{lllllll}
\hline \multirow{2}{*}{$\mathbf{T}_{\mathbf{s}} /{ }^{\circ} \mathbf{C}$} & \multicolumn{2}{l}{ Carboniferous } & Jurassic & \multicolumn{3}{l}{ Cretaceous } \\
\cline { 2 - 7 } & $\mathbf{A A} / \mathbf{m} . \mathbf{a}$. & $\mathbf{R}_{\mathbf{o m}} / \mathbf{\%}$ & $\mathbf{A A} / \mathbf{m} . \mathbf{a}$. & $\mathbf{R}_{\mathbf{o m}} / \boldsymbol{\%}$ & $\mathbf{A A} / \mathbf{m} . \mathbf{a}$. & $\mathbf{R}_{\mathbf{o m}} / \mathbf{\%}$ \\
\hline 50 & 290 & 0.525 & 170 & 0.491 & 110 & 0.466 \\
50 & 310 & 0.529 & 190 & 0.498 & 130 & 0.476 \\
75 & 290 & 0.705 & 170 & 0.657 & 110 & 0.62 \\
75 & 310 & 0.711 & 190 & 0.667 & 130 & 0.634 \\
100 & 290 & 0.932 & 170 & 0.863 & 110 & 0.81 \\
100 & 310 & 0.941 & 190 & 0.877 & 130 & 0.83 \\
125 & 290 & 1.242 & 170 & 1.139 & 110 & 1.062 \\
125 & 310 & 1.255 & 190 & 1.16 & 130 & 1.091 \\
150 & 290 & 1.704 & 170 & 1.543 & 110 & 1.424 \\
150 & 310 & 1.726 & 190 & 1.575 & 130 & 1.469 \\
175 & 290 & 2.489 & 170 & 2.203 & 110 & 2.001 \\
175 & 310 & 2.528 & 190 & 2.259 & 130 & 2.076 \\
200 & 290 & 4.14 & 170 & 3.502 & 110 & 3.083 \\
200 & 310 & 4.232 & 190 & 3.623 & 130 & 3.235 \\
\hline
\end{tabular}

\subsection{Comparison of Temperature and Time on the Metamorphic Degree}

In general concept, it can be qualitatively said that, regarding to improve coal metamorphism, increasing temperature is more effective than extending the time. But there have never been quantitative data to compare the magnitude of the two effects.

Equation (2) indicates that the Ro is a binary (temperature
$\mathrm{T}$ and time t) function. Higher mathematical methods cannot find the influence of temperature and time on the degree of deterioration.

The full differentiation of equation (2) [12]:

$$
\mathrm{dR}_{\mathrm{o}}=\left(\frac{\partial \mathrm{R}_{\mathrm{o}}}{\partial \mathrm{t}}\right)_{\mathrm{T}} \mathrm{dt}+\left(\frac{\partial \mathrm{R}_{\mathrm{o}}}{\partial \mathrm{T}}\right)_{\mathrm{t}} \mathrm{dT}
$$

There are two terms on the right side of the equation (3). The first term is the partial derivative of time under the temperature $\mathrm{T}$ as constant, which indicating the contribution of time to the change of metamorphic degree; the second term is the temperature partial derivative under the time $t$ as constant, which indicating the contribution of temperature to the change of the metamorphic degree.

In order to comparing the magnitude of the two effects, a "time-temperature ratio $t / T$ " is defined as the equivalent of several million years for increasing $1^{\circ} \mathrm{C}$. When the time-temperature ratio is greater than unit means the impact of increasing $1{ }^{\circ} \mathrm{C}$ temperature is larger than extending one million year time. The time-temperature ratio is easy to calculated by the second term of the right hand side of the equation (3) divides the first term of the right hand side of the equation (3).

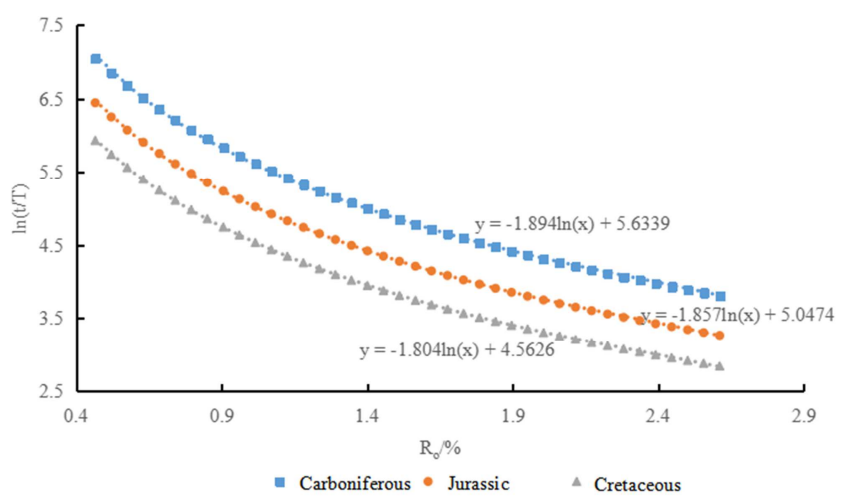

Figure 2. Relationship between vitrinite reflectance and time temperature ratio calculated by advanced mathematics method in three coal forming periods.

In any case (different coal forming period, different reflectivity), the effect of increasing $1^{\circ} \mathrm{C}$ temperature is greater than the effect of extending 1 million years. Even when the Cretaceous $\mathrm{R}_{\mathrm{o}}=6.1 \%$ of high coal grade III, the time-temperature ratio was $\mathrm{t} / \mathrm{T}=3.67$, meaning the effect of increasing $1^{\circ} \mathrm{C}$ temperature is equivalent to an extension of 3.67 million years. Comparing the time temperature ratio of different coal forming periods and different coal grades can show the temperature impact significance.

During the same coal forming period, the temperature effect decreased significantly with the reflectivity increasing;

At the same reflectivity, the temperature effect significance also decreases as the coal forming period younger.

\section{Conclusion}

Qualitative analysis and quantitative analysis should be 
unified and complementary; qualitative analysis is the basic premise of quantitative analysis, no quantitative quantification is a blind and worthless quantification; quantitative analysis makes it more scientific and accurate, it can promote qualitative analysis to draw extensive and in-depth conclusions. Quantitative analysis must be based on qualitative prediction, the two complement each other, qualitative is the basis of quantitative, quantitative is the combination of the two flexible use to achieve the best results.

The $\mathrm{Wu}$ temperature-time-reflectivity can calculate the minimum metamorphic temperature based on the known time and the reflectivity, or the maximum reflectivity based on the known time and the temperature.

Defining the effect of increasing $1{ }^{\circ} \mathrm{C}$ temperature is equivalent to the effect of extending several million years for a time-temperature ratio. The temperature ratio required to increase the reflectivity is varied between coal formation periods and at different coal grades. During the same coal forming period, the temperature effect decreases significantly with the reflectivity decreasing.

\section{References}

[1] Hu Zhongya. Effect of temperature, time and pressure on coalification [J]. Silicon Valley, 2010, (08): 4.

[2] Zhang Shuangquan. Coal Chemistry [M]. Xu Zhou: China University of Mining and Technology: 2015.

[3] Wu Chonglong, Yang Qi, Liu Gang, et al. Principles and methods of thermodynamics for analysis of coal metamorphism [J]. Journal of China Coal Society, 1997, 22 (3): 225-229.

[4] Yang Qi. A study on coal metamorphism in China [J]. Earth Science-Journal of China University of Geosciences, 1989, 14 (4): 341-345.

[5] Yang Qi. Superimposed metamorphism of Chinese coal [J]. Earth Science-Journal of China University of Geosciences, 1999, 6 (Z1): 1-8.

[6] Yang Qi, Wu Chonglong, Tang Dazhen, et al. Coal metamorphism in China [J]. Earth Science-Journal of China University of Geosciences, 1996, 21 (3): 311-319.

[7] Hood A, Gutjahr C C M, Heacock R H. Organic metamorphism and the generation of petroleum [J]. Bull. AAPG, 1975, 59 (6): 986-996.

[8] Bostick N H, Cashman S M, McCulloh T H, et al. Gradients of vitrinite reflectance and present temperature in the Los Angeles and Ventura Basins, California. In: Oltz D F, ed. Low temperature metamorphism of kerogen and clay minerals. Los Angeles: Pacific Section, SEPM (Society for Sedimentary Geology), 1979, 65-96.

[9] Method of determining microscopically the reflectance of vitrinite in coal. GB/T 6948-2008.

[10] Li Wenhua, Bai Xiangfei, Yang Jinhe, et al. Correspondence between mean maximum reflectance of Vitrinite and classification of bituminous coals [J]. Journal of China Coal Society, 2006, 31 (3): 342-345.

[11] Classification of coalification degree by vitrinite reflectance. MT/T 1158-2011.

[12] Xuemei Zhang, Dong Li, Qinghua Ma, et al. Quantitative Calculation of Temperature-Time-Coal Metamorphism [J]. Advances in Geosciences, 2021, 11 (7): 937-946. 